\title{
Climatic Conditions for modelling the Northern Hemisphere ice sheets throughout the ice age cycle
}

\author{
A. Abe-Ouchi ${ }^{1,2}$, T. Segawa ${ }^{2}$, and F. Saito ${ }^{2}$ \\ ${ }^{1}$ Center for Climate System Research, University of Tokyo, 5-1-5 Kashiwanoha, Kashiwa, 277-8568, Japan \\ ${ }^{2}$ Frontier Research Center for Global Change, Japan Agency for Marine-Earth Science and Technology, 3173-25 \\ Showamachi, Kanazawa, Yokohama, Kanagawa, 236-0001, Japan
}

Received: 15 December 2006 - Published in Clim. Past Discuss.: 6 February 2007

Revised: 30 May 2007 - Accepted: 27 June 2007 - Published: 19 July 2007

\begin{abstract}
The ice sheet-climate interaction as well as the climatic response to orbital parameters and atmospheric $\mathrm{CO}_{2}$ concentration are examined in order to drive an ice sheet model throughout an ice age cycle. Feedback processes between ice sheet and atmosphere are analyzed by numerical experiments using a high resolution General Circulation Model (GCM) under different conditions at the Last Glacial Maximum. Among the proposed processes, the ice albedo feedback, the elevation-mass balance feedback and the desertification effect over the ice sheet were found to be the dominant processes for the ice-sheet mass balance. For the elevation-mass balance feedback, the temperature lapse rate over the ice sheet is proposed to be weaker than assumed in previous studies. Within the plausible range of parameters related to these processes, the ice sheet response to the orbital parameters and atmospheric $\mathrm{CO}_{2}$ concentration for the last glacial/interglacial cycle was simulated in terms of both ice volume and geographical distribution, using a threedimensional ice-sheet model. Careful treatment of climateice sheet feedback is essential for a reliable simulation of the ice sheet changes during ice age cycles.
\end{abstract}

\section{Introduction}

Climate change during the past 500000 years is characterized by the wax and wane of the Northern hemisphere ice sheets with a periodicity of about 100 thousand years (kyr), known as glacial and interglacial cycles or ice age cycles (Imbrie et al., 1993). For the Last Glacial Maximum (LGM), not only the total ice volume but also the maximum extent of the Northern Hemisphere ice sheets, such as the Laurentide and Fenno-Scandian ice sheets, are well constrained by observational data (Peltier, 1994, 2004; Clark and Mix, 2002;

Correspondence to: A. Abe-Ouchi

(abeouchi@ccsr.u-tokyo.ac.jp)
Dyke et al., 2002; Svendsen et al., 2004). To explain why the ice sheets in the Northern Hemisphere grew to the size and extent that has been observed, and why they retreated quickly at the termination of each $100 \mathrm{kyr}$ cycle is still a challenge (Tarasov and Peltier, 1997a; Berger et al., 1998; Paillard, 1998; Paillard and Parrenin, 2004). Although it is now broadly accepted that the orbital variations of the Earth influence climate changes (Milankovitch, 1930; Hays et al., 1976; Berger, 1978), the large amplitude of the ice volume changes and the geographical extent need to be reproduced by comprehensive models which include nonlinear mechanisms of ice sheet dynamics (Raymo, 1997; Tarasov and Peltier, 1997b; Paillard, 2001; Raymo et al., 2006). Moreover, it is important to explain the geographical extent of the ice sheets, because this has a substantial influence on the climate and the ice sheet itself. Several studies using simple atmospheric models or General Circulation Models (GCMs) have shown that the high albedo and high altitude of the ice sheets can change the temperature, precipitation and the atmospheric circulation over broad spatial scales (Hansen et al., 1984; Manabe and Broccoli, 1985; Broccoli and Manabe, 1987; Rind, 1987; Shinn and Barron, 1989; Felzer et al., 1996; Cook and Held, 1998; Krinner and Genthon, 1999; Kageyama and Valdes, 2000; Roe and Lindzen, 2001).

Several studies with ice sheet models have been conducted in order to simulate the extent of the Northern Hemisphere ice sheets at the Last Glacial Maximum and/or their change during the glacial - interglacial cycle. Although it is straightforward, the direct coupling between a sophisticated climate model such as a GCM and an ice sheet model is still prohibitively computationally expensive. There are three alternative approaches which have been used to set up the climatic conditions for the past and drive a model of the Northern Hemisphere ice sheets. The first approach involves modelling the ice sheet change between the glacial and interglacial stages with a simple climate model driven by both

Published by Copernicus Publications on behalf of the European Geosciences Union. 
the orbital forcings and the changes in the atmospheric concentration of carbon dioxide (Deblonde and Peltier, 1991; Marsiat, 1994; Tarasov and Peltier, 1997a,b, 1999; Charbit et al., 2005). With this approach, the mechanism of ice sheet changes can be studied, but it is not clear what the effect on the results is of missing processes in the simplified model. The second approach involves forcing an ice sheet model with climatology obtained by running time slice experiments with a GCM or a simpler climate model at given time periods such as the LGM or the glacial inception (about 115 thousand years before present (ka BP)) (Verbitsky and Oglesby, 1992; Schlesinger and Verbitsky, 1996; Thompson and Pollard, 1997; Fabre et al., 1997, 1998; Ramstein et al., 1997; Huybrechts and T'siobbel, 1997; Pollard and PMIP Participating Groups, 2000; Yamagishi et al., 2005). The aim of this approach is to investigate the possibility of the maintenance or existence of the Northern Hemisphere ice sheets under steady state climatic forcing. Therefore this approach does not consider changes in the climatic conditions. The third approach deals with ice sheet changes for a given period (e.g. for one ice age cycle or for the deglaciation period since the LGM) by using time slice experiments of climate models at the LGM and present-day and interpolating the climatic field between the two time slices by using the time series of oxygen isotope data of ice cores from Greenland (Huybrechts and T'siobbel, 1995; Greve et al., 1999; Marshall et al., 2000, 2002; Marshall and Clark, 2002; Charbit et al., 2002; Zweck and Huybrechts, 2005). With this approach, the transient behavior of the ice sheets and the influence of the climate on it can be examined in detail. However, the ultimate cause of the ice sheet changes cannot be identified with this method because the paleoclimatic data such as the oxygen isotope from ice core is used to drive the ice sheet model.

In this study, we reexamine the climatic factors that control the ice sheet changes with several experiments using a GCM. Critical parameters, such as lapse rate, which are often assumed in an ice sheet model are also examined. Based on the examination of climatic factors, we present a new method for using ice sheet models to study the impact of the orbital parameters and atmospheric $\mathrm{CO}_{2}$ concentration upon the change of the Northern Hemisphere ice sheets. The climate and the ice sheet models used in the study are introduced in Sect. 2. In Sect. 3, the experimental setup is presented and the influence of the ice sheets on the climatic conditions through the albedo feedback, the elevation-mass balance feedback and the stationary wave feedback (Cook and Held, 1998) are discussed. Here we focus on the feedbacks related to temperature since the processes related to precipitation over the ice sheets were presented in Yamagishi et al. (2005). The influence of the orbital parameters and atmospheric $\mathrm{CO}_{2}$ on the climate is briefly examined at the end of Sect. 3. The experimental design and the result of the runs for the past $120 \mathrm{kyr}$ using an ice sheet model are presented and discussed in Sect. 4 and the conclusions are summarized in Sect. 5.

\section{Model description}

\subsection{Climate model}

In order to examine the response of the climate to changes in the orbital parameters, $\mathrm{CO}_{2}$ and the ice sheets, a General Circulation Model developed at the Center for Climate System Research (CCSR) and the National Institute for Environmental Studies (NIES), called CCSR/NIES AGCM5.4 is used (Numaguti et al., 1997). This model was also used for the LGM studies and inter-comparison of the climate at $6 \mathrm{ka}$ and the LGM lead by the first Paleoclimate Modelling Intercomparison Project (PMIP) and also for the IPCC Third Assessment Report (TAR). For the present study the model resolutions used were T106 with 20 sigma levels vertically and T42 with 11 levels. The model includes cumulus parameterization, cloud-radiation interactions, and surface processes. Detailed description of the model is given in $\mathrm{Nu}$ maguti et al. (1997) and Emori et al. (1999). This AGCM has subsequently been further developed and coupled with an OGCM (the collaboration now involving researchers at a third institute, Frontier Research Centre for Global Change (FRCGC)), the latest version being called MIROC3.2 (K-1 model developers, 2004). This latest version was used for the global warming experiments reported in the IPCC Assessment Report 4 (AR4) and PMIP2.

\subsection{Ice sheet model}

The numerical ice-sheet model in this paper, called IcIES (Ice sheet model for Integrated Earth system Studies), is based on the model described in Saito and Abe-Ouchi (2004), reprojected onto the spherical grid system. The model couples the ice-sheet dynamics to the surface mass balance and the bedrock deformation as explained below.

\subsubsection{Ice sheet and bedrock deformation}

The ice-sheet dynamic routine computes the evolution of ice thickness and temperature in the shallow ice approximation (Hutter, 1983) including thermodynamics which relates flow velocity and temperature. The model only computes the evolution of grounded ice but not floating ice shelves. The ice sheet model has been tested for the present Greenland and Antarctic ice sheets (Saito and Abe-Ouchi, 2004, 2005). The basic part of the model used in the present paper is the same as that used in Saito and Abe-Ouchi (2005) except two processes described below. The difference from the model used in Saito and Abe-Ouchi $(2005,2004)$ are the parameterization of basal sliding and the treatment of the temperature field in the bedrock.

The sliding velocity is related to the gravitational driving stress according to Payne (1999),

$$
\boldsymbol{v}_{B}=-A_{s}\left[\rho_{I} g H \nabla_{H} h\right],
$$


where $v_{B}$ is the basal sliding velocity, $\rho_{I}=910 \mathrm{~kg} \mathrm{~m}^{-3}$ is the density of ice, $g=9.81 \mathrm{~m} \mathrm{~s}^{-1}$ is acceleration of gravity, $H$ is the ice thickness, and $h$ is the surface elevation. The parameter $A_{s}$ is set at $0.01 \mathrm{~m} \mathrm{yr}^{-1} \mathrm{~Pa}^{-1}$, which is chosen within the range of uncertainties used in the sensitivity studies presented in Marshall et al. (2002).

Basal sliding is assumed to occur only when the basal ice is at the pressure melting point. The temperature distribution of the lithosphere is considered as in Greve (1997):

$$
\frac{\partial T}{\partial t}+\frac{\partial b}{\partial t} \frac{\partial T}{\partial z}=\frac{k_{R}}{\rho_{R} c_{R}} \frac{\partial^{2} T}{\partial z^{2}},
$$

where $T$ is the temperature, $b$ is the bedrock elevation, $k_{R}=3.0 \mathrm{~W} \mathrm{~m}^{-1} \mathrm{~K}^{-1}$ is the heat conductivity of the lithosphere, $\rho_{R}=2700 \mathrm{~kg} \mathrm{~m}^{-3}$ is the density of the lithosphere and $c_{R}=1000 \mathrm{~J} \mathrm{~kg}^{-1} \mathrm{~K}^{-1}$ is the specific heat of the lithosphere. Thickness of the upper lithosphere layer accounted for by the model is set to a constant value of $5 \mathrm{~km}$ (Greve, 1997). We use the depth relative to contemporaneous bedrock elevation to formulate Eq. (2) in the model. The geothermal heat flux at the bottom of the lithosphere is set at a constant value of $42 \mathrm{~mW} \mathrm{~m}^{-2}$ in all experiments. It is worth mentioning that the geothermal heat flux may reach between 50 and $150 \mathrm{~mW} \mathrm{~m}^{-2}$ in the Western part of Canada, while the present value of $42 \mathrm{~mW} \mathrm{~m}^{-2}$ is probably valid for the Eastern and central parts and for the major part of Fennoscandia. Changes in the glacier bed elevation are calculated by an equation expressing local isostatic rebound:

$$
\frac{\partial b}{\partial t}=\frac{1}{\tau_{b}}\left(b-e+\frac{\rho_{I}}{\rho_{M}} H\right)
$$

where $\rho_{M}=3300 \mathrm{~kg} \mathrm{~m}^{-3}$ is the density of the mantle, and $e$ is the prescribed equilibrium elevation of bedrock with no ice loading, which is obtained with the assumption that the present condition is in an equilibrium. The time constant for isostatic rebound, $\tau_{b}$, is set at 5000 years in the present paper (Tarasov and Peltier, 1997b; Marshall et al., 2000). Hudson Bay is treated as land toward which the ice sheet is allowed to advance. Dynamics of both ice shelf and grounding line are not included in the present model. Calving is assumed to occur completely at the bathymetric perimeter of $-500 \mathrm{~m}$ depth except for a deeper but closed part in Hudson Bay. This is the same procedure adopted by Tarasov and Peltier (1999) except that they apply $-400 \mathrm{~m}$. A semi-implicit scheme (Hindmarsh and Payne, 1996) is applied for solving the mass balance ice thickness equation. The over-implicit scheme (Hindmarsh, 2001; Greve et al., 2002) with the coefficient 1.5 (the weighting factor for the flux at the next time step when solving the mass balance equation) is adopted.

\subsubsection{Surface mass balance model}

The surface mass balance is parameterized by a Positive Degree-Day (PDD) method (Reeh, 1991), which is used as input to the ice-sheet model. This method relates ablation to both air temperature and snow accumulation. The amount of melting is computed as the product of the number of positive degree days and the PDD factor obtained by observations. It considers: the possibility for melting even if the average daily temperature is below the freezing point; different melt rates for snow and ice due to the difference in the albedo Braithwaite and Olesen, 1989); and production of superimposed ice and warming created by the phase change. This method is adopted in most numerical studies with ice sheet models (Ritz et al., 1997; Greve, 2000; Huybrechts et al., 2002). In this study, the PDD factor for snow melting is set at $3 \mathrm{~mm} \mathrm{day}^{-1} \mathrm{~K}^{-1}$ water equivalent following Braithwaite (1995) and Huybrechts et al. (1991), and that for ice melting is set at $8 \mathrm{~mm} \mathrm{day}^{-1} \mathrm{~K}^{-1}$ water equivalent following Reeh (1991) and Huybrechts et al. (1991). Standard deviation of the daily temperature is assumed to be $5 \mathrm{~K}$. It is assumed that $60 \%$ of melt snow re-freezes onto superimposed ice. van de Wal (1996) shows that the PDD method and energy balance method yields very similar results.

Accumulation rate is parameterized partly based on the method presented by Marshall et al. (2002) as follows:

$$
A_{c c}=A_{\mathrm{ref}} \times\left(1+d_{\mathrm{P}}\right)^{\Delta T_{s}}
$$

where $A_{c c}$ is the accumulation rate, $A_{\text {ref }}$ is a reference accumulation, $d_{\mathrm{P}}$ is temperature aridity (see Marshall et al., 2002), and $\Delta T_{S}$ is the difference in surface temperature to the reference state. In this experiment, CMAP (Xie and Arkin, 1996) was used as the present reference precipitation as in Yamagishi et al. (2005). In contrast to Marshall et al. (2002), here the accumulation lapse rate (elevationaccumulation feedback) is neglected.

The surface temperature, which is used as input for both the ice-sheet and surface mass balance models, is parameterized as follows:

$$
T_{s}=T_{\text {ref }}+\Delta T_{\text {ice }}+\Delta T_{\mathrm{co} 2}+\Delta T_{\text {insol }}+\Delta T_{\text {nonlinear }}
$$

where $T_{S}$ is the surface temperature, $T_{\text {ref }}$ is the reference temperature, $\Delta T_{\text {ice }}$ denotes the effect of total atmospheric response to changes in ice sheet size, $\Delta T_{\mathrm{CO}_{2}}$ is the change in temperature according to change in concentration of atmospheric $\mathrm{CO}_{2}, \Delta T_{\text {insol }}$ is the change in temperature according to changes in insolation, $\Delta T_{\text {nonlinear }}$ is residual term due to other effects. The reference temperature field $T_{\text {ref }}$ used in the present paper is based on the present climatology (reanalyzed European Centre for Medium-Range Weather Forecasts data) as explained in Yamagishi et al. (2005). Since we assumed in the experiment that Hudson Bay is not ocean but land, we modify the reference temperature over Hudson Bay by interpolating the coastal values. Each term of Eq. (5) is described and tested in Sect. 3. 
Table 1. Boundary conditions for AGCM experiments. The terms $E, O, P$ indicated as orbital condition correspond to eccentricity, obliquity in degree, angular precession (longitude of perihelion) in degree, respectively. They are: $E=0.01672, O=23.45, P=102.04$ at $0 \mathrm{ka}$, and $E=0.018994, O=22.949, P=114.42$, at the LGM. The $\mathrm{CO}_{2}$ concentration for $0 \mathrm{ka}$ and the LGM are $345 \mathrm{ppm}$ and $200 \mathrm{ppm}$, respectively.

\begin{tabular}{|c|c|c|c|c|c|c|c|c|}
\hline \multirow[t]{2}{*}{ Experiment } & \multirow[t]{2}{*}{ Resolution } & \multirow[t]{2}{*}{ Ocean } & \multicolumn{3}{|c|}{ Orbital condition } & \multirow[t]{2}{*}{$\mathrm{CO}_{2}$} & \multicolumn{2}{|c|}{ Ice Sheet } \\
\hline & & & $E$ & $O$ & $P$ & & extent & topography \\
\hline CTLH & T106L20 & 0 ka SSTfix & & $0 \mathrm{ka}$ & & $0 \mathrm{ka}$ & $0 \mathrm{ka}$ & $0 \mathrm{ka}$ \\
\hline LGMnice & T106L20 & LGM SSTfix & & LGM & & LGM & $0 \mathrm{ka}$ & $0 \mathrm{ka}$ \\
\hline LGMflat & T106L20 & LGM SSTfix & & LGM & & LGM & LGM & $0 \mathrm{ka}$ \\
\hline LGMfull & T106L20 & LGM SSTfix & & LGM & & LGM & LGM & LGM \\
\hline M21nice & T42L11 & slab ocean & & LGM & & LGM & $0 \mathrm{ka}$ & $0 \mathrm{ka}$ \\
\hline M21flat & T42L11 & slab ocean & & LGM & & LGM & LGM & $0 \mathrm{ka}$ \\
\hline M12flat & T42L11 & slab ocean & & LGM & & LGM & $12 \mathrm{ka}$ & $0 \mathrm{ka}$ \\
\hline M12full & T42L11 & slab ocean & & LGM & & LGM & $12 \mathrm{ka}$ & $12 \mathrm{ka}$ \\
\hline MOCTL & T42L11 & slab ocean & & $0 \mathrm{ka}$ & & $0 \mathrm{ka}$ & $0 \mathrm{ka}$ & $0 \mathrm{ka}$ \\
\hline M21O1C1 & T42L11 & slab ocean & 0.05 & 23.45 & 102.04 & LGM & LGM & LGM \\
\hline M21O1C2 & $\mathrm{T} 42 \mathrm{~L} 11$ & slab ocean & 0.05 & 23.45 & 102.04 & $280 \mathrm{ppm}$ & LGM & LGM \\
\hline M21O1C3 & T42L11 & slab ocean & 0.05 & 23.45 & 102.04 & $0 \mathrm{ka}$ & LGM & LGM \\
\hline $\mathrm{M} 21 \mathrm{O} 2 \mathrm{C} 1$ & T42L11 & slab ocean & 0.05 & 23.45 & 282. & LGM & LGM & LGM \\
\hline $\mathrm{M} 21 \mathrm{O} 2 \mathrm{C} 3$ & T42L11 & slab ocean & 0.05 & 23.45 & 282. & $0 \mathrm{ka}$ & LGM & LGM \\
\hline M0O1C2 & T42L11 & slab ocean & 0.05 & 23.45 & 102.04 & $280 \mathrm{ppm}$ & $0 \mathrm{ka}$ & $0 \mathrm{ka}$ \\
\hline $\mathrm{M} 0 \mathrm{O} 2 \mathrm{C} 2$ & T42L11 & slab ocean & 0.05 & 23.45 & 282. & $280 \mathrm{ppm}$ & $0 \mathrm{ka}$ & $0 \mathrm{ka}$ \\
\hline M0O8C2 & T42L11 & slab ocean & 0 . & 25.5 & 0 . & $280 \mathrm{ppm}$ & $0 \mathrm{ka}$ & $0 \mathrm{ka}$ \\
\hline M0O9C2 & T42L11 & slab ocean & 0 . & 22. & 0 . & $280 \mathrm{ppm}$ & $0 \mathrm{ka}$ & $0 \mathrm{ka}$ \\
\hline
\end{tabular}

\subsubsection{Ice sheet model set-up}

The ice-sheet thickness, bedrock deformation and surface mass balance are computed on the same grid-system on the spherical coordinates. The horizontal model domain spans from $30^{\circ} \mathrm{N}$ to $89^{\circ} \mathrm{N}$ and $360^{\circ}$ in longitudinal direction with periodic boundary conditions. The horizontal grid resolution is $1^{\circ}$ in both coordinate directions. This resolution may actually be insufficient for accurate modelling of the changes in the ice-sheet over the ice-age cycles, however, higher resolution configurations (such as $0.5^{\circ}$ ) have not yet been explored, and further consideration of this issue is future work outside the scope of this paper. The vertical grid is divided into 26 levels. The model time step is 2 years.

\section{Evaluation of the climate over the ice sheet with GCM experiments}

The main focuses in this section are on the relative contribution to the climate over the ice sheet of: (a) the ice sheet itself; (b) the orbital parameters; (c) the atmospheric $\mathrm{CO}_{2}$ concentration. The contribution of the ice sheet itself to the climate is through the high ice albedo and the high and massive ice topography. Since a GCM is used to evaluate the climate in this study, the effects of cloud feedback and water vapor feedback are implicitly included in the results. No attempt is made to separate the effects of the orbital parameters and $\mathrm{CO}_{2}$ concentration from each other or from the effect due to the ice sheet itself.

The climate variables which act as boundary conditions to the ice-sheet are monthly mean temperature and precipitation. In this study, the northern hemispheric summer temperature is analyzed, since the surface ice melting of the northern ice sheets is primarily determined by the summer temperature in June, July and August (Ohmura, 2001). The precipitation over the ice sheets and its relation to temperature are discussed at the end of Sect. 3.2.

\subsection{Experimental design}

A total of 19 experiments, summarized in Table 1, were designed to study the factors that determine the surface temperature over the ice sheets. Three groups of experiments were performed as follows.

The first group uses a high resolution (T106, $1.1^{\circ}$ in latitude and longitude) atmospheric GCM with fixed sea surface temperature (SST) for the study of the ice sheet-atmosphere interaction also described in Yamagishi et al., 2005; Jost et al., 2005. Experiments named CTLH and LGMfull are based on the protocol of The Paleoclimate Modelling Intercomparison Project (PMIP; Joussaume and Taylor, 1995), where CTLH represents a present day 0 ka control simulation and LGMfull is the LGM experiment. Insolation parameters are set at the LGM values and the $\mathrm{CO}_{2}$ concentration is set at $200 \mathrm{ppm}$. As boundary conditions for the LGM experiment, 
Table 2. Effects on difference of the surface air temperature due to the change in the climate (the LGM and present day) and the effects of ice sheet and others obtained by GCM experiments. Summer (June, July and August) and winter (December, January, February) mean over three ice sheets are shown. Ice sheet effects are divided into the latter three components, albedo, lapse rate and the residual. The values of JJA correspond to the Figs. 1a-c and $2 \mathrm{a}-\mathrm{c}$.

\begin{tabular}{|c|c|c|c|}
\hline \multicolumn{4}{|c|}{ JJA } \\
\hline Effect & Greenland & Laurentide & Fennoscandian \\
\hline Total & -18.0 & -21.1 & -17.6 \\
\hline $\mathrm{CO}_{2}$, Orbit and SST & -4.4 & -4.2 & -2.9 \\
\hline Ice sheet & -13.6 & -16.9 & -14.7 \\
\hline Albedo & -5.3 & -10.2 & -9.8 \\
\hline Lapse rate & -4.1 & -6.4 & -4.1 \\
\hline Residual & -4.2 & -0.3 & -0.76 \\
\hline \multicolumn{4}{|c|}{ DJF } \\
\hline Total & -18.1 & -14.2 & -22.0 \\
\hline $\mathrm{CO}_{2}$, Orbit and SST & -8.9 & 2.0 & -1.6 \\
\hline Ice Sheet & -9.3 & -16.2 & -20.4 \\
\hline Albedo & -5.3 & -12.7 & -25.0 \\
\hline Lapse Rate & -4.1 & -6.4 & -4.1 \\
\hline Residual & 0.1 & 2.9 & 8.8 \\
\hline
\end{tabular}

CLIMAP data (CLIMAP, 1981) is used for the SST, ICE-4G is applied for the ice sheet topography (Peltier, 1994) and the greenhouse gas levels as well as the orbital parameters were used for the LGM level following the PMIP protocol. LGMflat is a sensitivity experiment, where the ice sheet covers the same area as in LGMfull but the thickness is set to $0 \mathrm{~m}$ except for Greenland and Antarctica, for which the present topography is taken. The distribution of surface albedo and other parameters is prescribed as in LGMfull. In the LGMnice experiment, the ice sheet and SST are the same as in CTLH, while $\mathrm{CO}_{2}$ and insolation parameters are set the same as in LGMfull. Each experiment is run for 11 or 13 model years, and the results for the last 10 years are used for the analysis. The computation time for one experiment was about 40 days per 10 model years on an NEC SX-5 with a single processor.

The second group of experiments is designed to examine the dependence of the climate on the size of the ice sheets. Similar experiments to those in the first group were performed but with different sized ice sheets leaving other conditions the same as given in Table 1. From the ICE-4G (Peltier, 1994) time slices, the ice sheet size at $12 \mathrm{ka}$ was chosen since its area is about half that at the LGM. For reasons of computational cost, a medium resolution, (T42, latitude and longitude $2.8^{\circ}$ for horizontal and 11 layers mainly in the troposphere for vertical resolution) is used for these experiments, but the slab ocean model is used to take into account the thermal feedback of the oceans. These experiment are called M21nice, M21flat, M12nice, M12flat and M0CTL. Each experiment was run for 50 model years, and the results for the last 10 years are used for the analysis.
The third group of experiments is designed to separate the influences of the atmospheric $\mathrm{CO}_{2}$ concentration and the orbital parameters. Extreme situations due to (1) different precession combined with large eccentricity and (2) extreme obliquities were chosen to examine the range of climatic condition due to different orbital parameters during the late Quaternary. $\mathrm{CO}_{2}$ levels of $200,280,345 \mathrm{ppm}$ were combined with different orbital parameters and ice sheet sizes (LGM or $0 \mathrm{ka})$ were chosen as given in Table 1 . These experiments are called $\mathrm{M} y \mathrm{O} l \mathrm{C} k$, where $y, l$ and $k$ denote the ice sheet distribution, the orbital condition and $\mathrm{CO}_{2}$ concentration, respectively. A medium resolution climate model with slab ocean was used.

Recently, during the second phase of PMIP (PMIP2), the experimental design of the LGM was updated, the major changes being introduction of atmosphere-ocean coupled GCMs (AOGCMs) and updating of the ice sheet topography with ICE-5G (Braconnot et al., 2007, http://www-lsce.cea. $\mathrm{fr} / \mathrm{pmip} 2 /$ ). We did not have computational resources to redo all the sensitivity experiments using the new protocol, but as additional analyses, we here report on the PMIP2 (from the PMIP2 database as of April 2006) results from fully coupled AOGCM experiments run for the LGM and the pre-industrial (hereafter CTL). Four models are used to discuss the role of the ice sheet in the climate, CCSM, HadCM3M2, IPSL and MIROC3.2. MIROC3.2 is the upgraded version of the model we are using in the rest of this paper (K-1 model developers, 2004). 


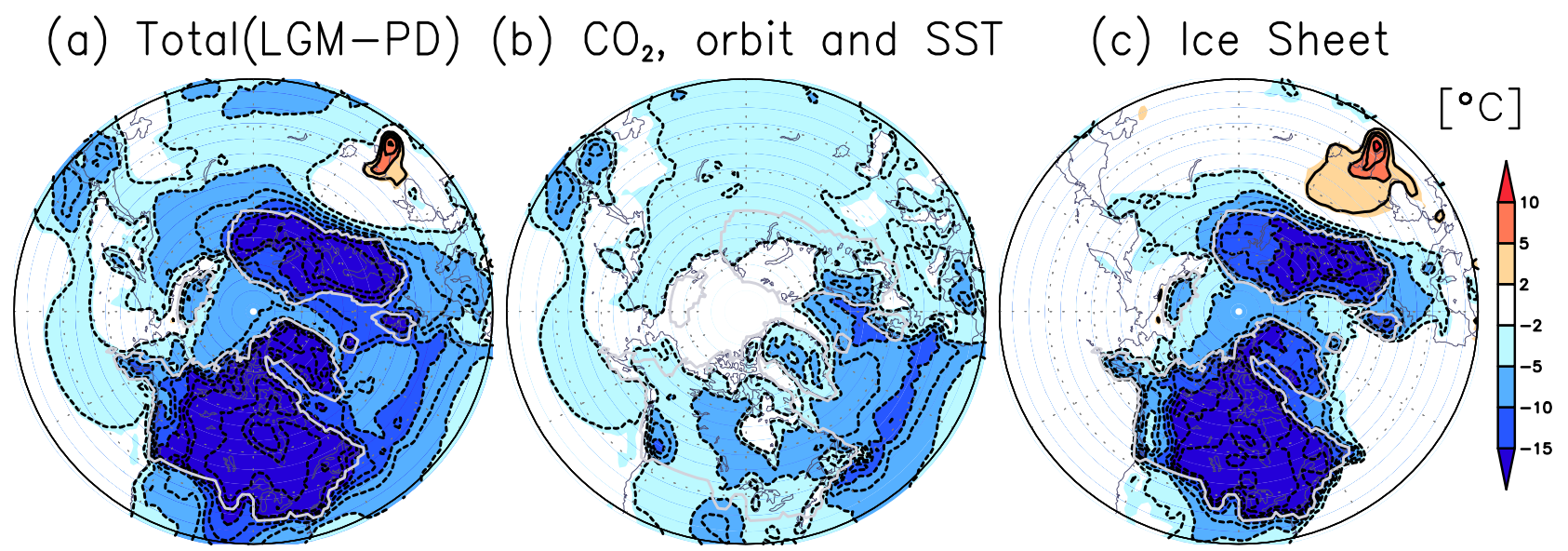

Fig. 1. Difference in summer surface air temperature (mean of June, July and August) in ${ }^{\circ} \mathrm{C}$ due to boundary conditions. (a) Difference between the LGM and present day (PD), (b) $\mathrm{CO}_{2}$ and SST effect by experiments (LGMnice-CTLH), (c) ice sheet effect by experiments (LGMfull-LGMnice). Contours are at: $-50,-45,-35,-30,-25,-20,-17.5,-15,-12.5,-10,-7.5,-5,-2.5,2.5,5,7.5,10,12.5$. Gray line in the figures indicates the ice sheet extent used in the GCM.

\subsection{Ice sheet-atmosphere feedback}

\subsubsection{Ice sheet vs other effects}

The effect of the ice sheet itself and the other effects upon the cooling are compared and obtained by the experiments LGMfull, LGMflat, LGMnice and CTLH. Air temperature differences are mainly analyzed for the summer season in Figs. 1 and 2, while the value of the summer and winter mean for the spatial mean over the ice sheets is displayed in Table 2

(the summer and winter means are the mean values for June, July, August and December, January, February respectively). The total cooling by the ice sheet itself is given by the difference LGMfull-CTLH, Fig. 1a, indicated by "total." The total cooling over the Greenland ice sheet is about $-18 \mathrm{~K}$ for both summer and winter, which is consistent with borehole measurements in Greenland (Dansgaard et al., 1993). Compared to this, the cooling due to other effects such as the $\mathrm{CO}_{2}$ effect, the orbital effect and the effect due to the difference in SST, LGMnice-CTLH, is shown in Fig. $1 b$. Figure 1c shows the cooling due to the existence of the ice sheet, given by the difference LGMfull-LGMnice. The cooling in Fig. 1c is much larger than that in Fig. 1b over the ice sheet region. Therefore, the cooling caused by the existence of the large ice sheets at the LGM is the dominant effect which should be treated separately.

\subsubsection{Albedo vs topography effects}

For the influence of the ice sheet itself, the high albedo and the high altitude of the ice sheet can both be important. LGMflat-LGMnice and LGMfull-LGMflat will here be assumed to be the high albedo effect (flat ice sheet effect) and ice topography effect, respectively. As in Table 2, the albedo effect is far larger than the topography effect. The ice topography effect can have a "local" effect and "non-local" effects. A well known "local" ice topography effect is the so-called "lapse rate effect", which causes cooling over the ice sheet just because of the locally high altitude. This was also addressed in Krinner and Genthon (1999) for the case of Antarctica by changing the surface elevation of Antarctica in a GCM. The non-local topography effect can be important through the influences upon the atmospheric circulation and/or cloud distribution (Shinn and Barron, 1989; Felzer et al., 1996; Cook and Held, 1998; Kageyama and Valdes, 2000; Roe and Lindzen, 2001). Altogether the ice sheet itself is separated into three categories, flat ice effect, lapse-rate effect and topography effect other than lapse rate effect (as a residual), which correspond to Fig. 2a, b, c, respectively. For the lapse rate effect, a lapse rate of $5 \mathrm{~K} \mathrm{~km}^{-1}$ was assumed. The summation of effects in Figs. 2a, b, c is equal to Fig. 1c.

In order to examine the lapse rate effect in the model, the local temperature changes due to the topography change (flat versus full) are examined. The summer lapse rate is shown and discussed in the following since the temperature in summer is important for the melt. The cooling due to the topography, namely LGMfull-LGMflat is plotted for the change of altitude for all grid points in the ice sheet area of this high resolution GCM as in Fig. 2d. The relation of $5{ }^{\circ} \mathrm{C}$ cooling per $1 \mathrm{~km}$ altitude change is shown as a red line. Although there is a large scatter, it is seen that the temperature drops as the altitude increases. Other lapse rates could be used which vary depending on the altitude or location, while a lapse rate larger than $7 \mathrm{~K} \mathrm{~km}^{-1}$ or smaller than $4 \mathrm{~K} \mathrm{~km}^{-1}$ is inconsistent with the overall feature. This is consistent with the finding of Krinner and Genthon (1999), who suggest a lapse rate of $5.5 \mathrm{~K} \mathrm{~km}^{-1}$, but is in contrast with other stud- 

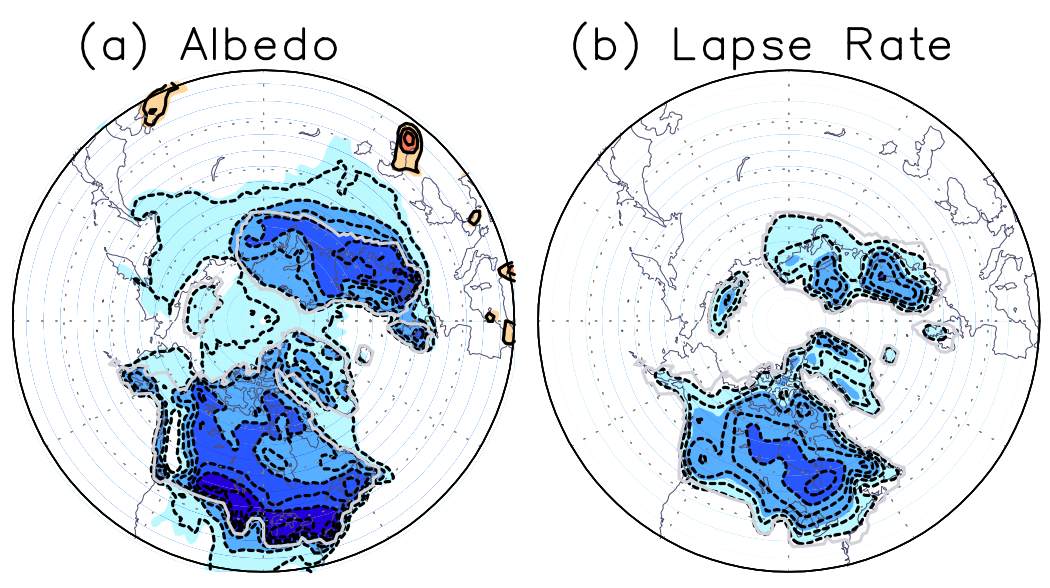

(d)

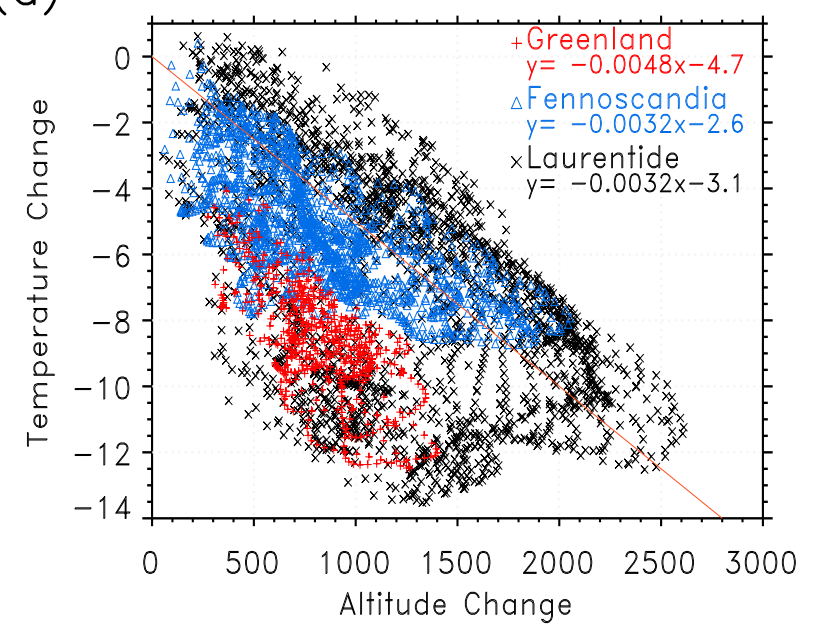

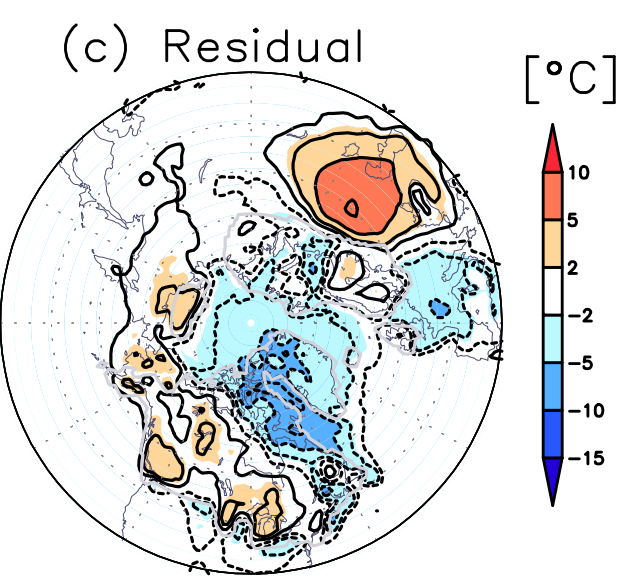

(e) Z500 anomaly

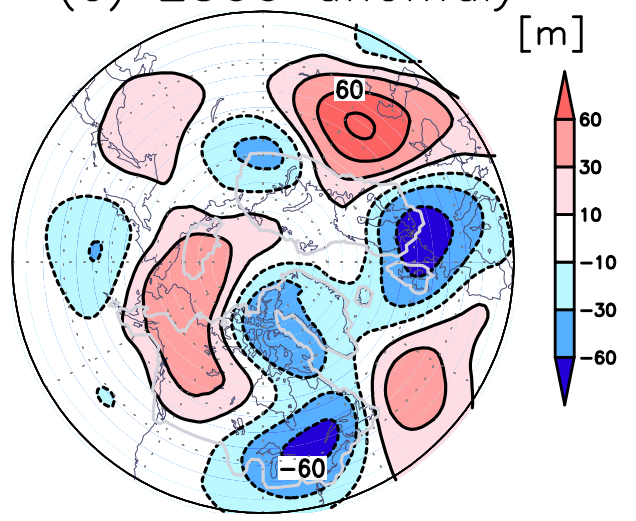

Fig. 2. (a-c) Difference in summer surface air temperature (mean of June, July and August) in ${ }^{\circ} \mathrm{C}$ due to boundary conditions. (a) Albedo effect by experiments (LGMflat-LGMnice), (b) Topography Lapse Rate Effect assuming a lapse rate $5 \mathrm{~K} \mathrm{~km}^{-1}$ for the given topography (LGMfull-LGMflat). Contours of figures (a) to (b) are the same as those of Fig. 1. (c) Topography effect other than the lapse rate effect as Residual. Contours are $-50,-45,-35,-30,-25,-20,-17.5,-15,-12.5,-10,-7.5,-5,-2.5,-1,1,2.5,5,7.5,10,12.5$. (d) Difference in summer surface temperature (mean of June, July and August) versus the difference in altitude for all the grid points over the ice sheet in the model. The red line corresponds to the relation of the lapse rate $-5^{\circ} \mathrm{C}$ per $1 \mathrm{~km}$. The red mark of scatter plots is for the Greenland ice sheet, the blue mark for the Fennoscandian ice sheet, and the black mark is for the Laurentide ice sheet. The linear regression values for the plotted temperature change data are shown in the figure. (e) Difference in summer geopotential height at $500 \mathrm{hPa}$ level due to ice sheet topography (LGMfull-LGMflat), but the zonal mean is subtracted. Contours are $-150,-120,-90,-60,-30,-10,10,30,60$, $90,120,150$. Gray line in the figures indicates the ice sheet extent used in the GCM.

ies which have conventionally used lapse rates of $8 \mathrm{~K} \mathrm{~km}^{-1}$ or $6.5 \mathrm{~K} \mathrm{~km}^{-1}$ to drive the ice sheet models (e.g. Fabre et al., 1997; Ramstein et al., 1997; Huybrechts and T'siobbel, 1997; Tarasov and Peltier, 1997a,b, 1999; Fabre et al., 1998; Greve et al., 1999; Pollard and PMIP Participating Groups, 2000; Marshall et al., 2000; Marshall and Clark, 2002; Marshall et al., 2002; Charbit et al., 2002, 2005; Zweck and Huybrechts, 2005). The temperature change shown in Fig. 2d is caused by a combination of changes in the remote ice sheets as well as local changes, as shown by the relatively large cooling over the Greenland ice sheet (red) and some parts of the Laurentide ice sheet (black) compared to the Fennoscandian ice sheet (blue). The overall geographical pattern of the scatter outside of a line (red line) corresponds to Fig. 2c. Except for the region around Greenland and the north-east side of the Laurentide ice sheet, the residuals shown in Fig. 2c are small compared to the albedo effect shown in Fig. 2a or the lapse rate effect shown in Fig. 2b. Detailed analysis of the seasonal as well as spatial change of lapse rate should be investigated as a future topic.

The temperature difference in Fig. $2 \mathrm{c}$ must be related to an atmospheric circulation effect such as the "Stationary 


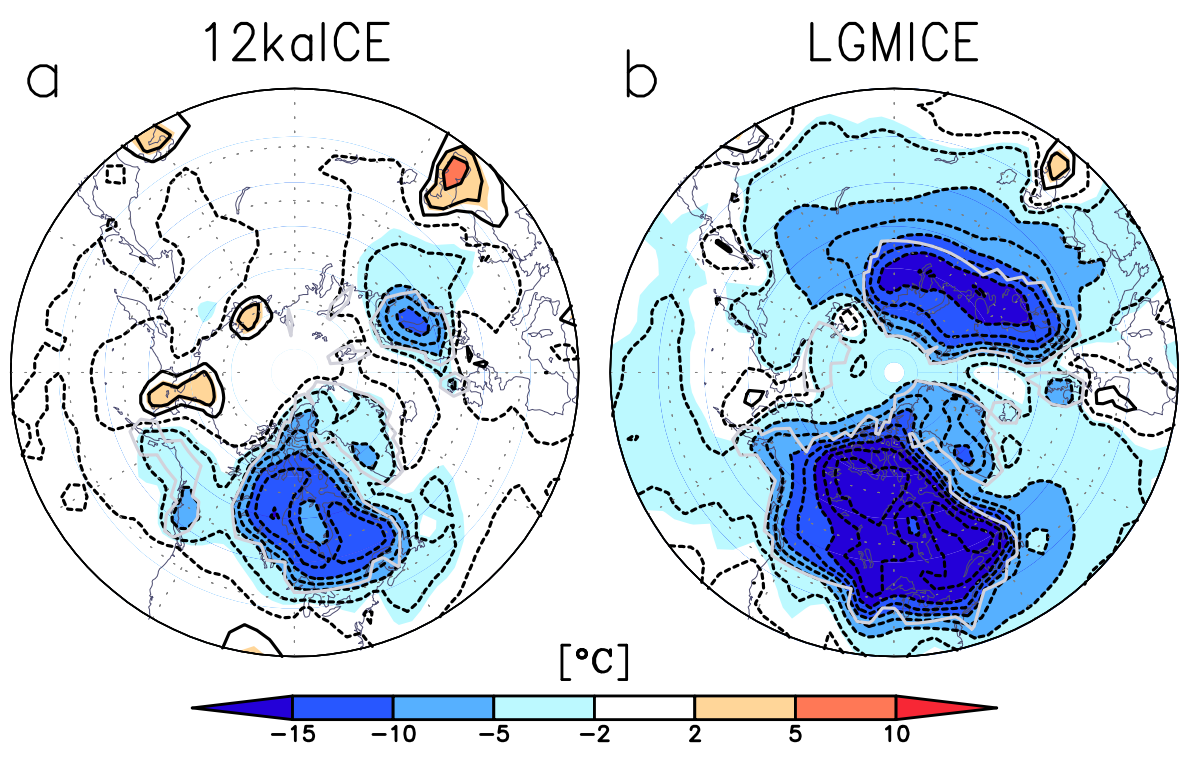

Fig. 3. Same as Fig. 2(a), but for different sizes of "flat" ice sheet (at the LGM and $12 \mathrm{ka}$ ). (a) M12flat-M21nice, (b) M21flat-M21nice.

wave effect" studied in Cook and Held (1998). To examine the stationary waves in our model, the summer geopotential height difference at $500 \mathrm{hPa}$ level due to the ice sheet topography, LGMfull-LGMflat, is shown in Fig. 2e. The surface topography induces higher height on the west side of the Laurentide sheet and lower height in the east. Around the Fennoscandian ice sheet, a series of waves from east to west seems to be caused by both large ice sheets in the Northern Hemisphere. The pattern is similar to the pattern in the surface temperature changes in Fig. 2c, which is consistent with the findings of Cook and Held (1998).

The result of the ice sheet effect seems to be dependent on the size of the ice sheet. Figure 3 shows the flat ice sheet effect ("albedo effect") for the $12 \mathrm{ka}$ ice sheet size and the LGM ice sheet size. The result is that the larger the ice sheet size, the larger the cooling. The cooling over the flat ice sheet is as large as $-15 \mathrm{~K}$ over the ice sheet at the LGM, which is distinctively larger than the cooling outside the ice sheet. Since the climate model used in these experiments is a slab mixed layer model, the ice sheet causes cooling outside the region actually occupied by the ice sheet.

In summary, for the summer temperature over the ice sheet, the dominant effects are the albedo effect and the lapse rate effect shown in Figs. 2a and b, respectively. The effect due to the stationary wave effect shown in Fig. $2 \mathrm{c}$ is a secondary effect compared to the albedo and lapse rate effects. We propose that: (1) the dependence of the albedo effect upon the area of the ice sheet should be taken into account and (2) a weaker lapse rate than suggested by previous studies should be assumed for ice sheet modelling.

\subsubsection{Analysis of PMIP2 models}

Finally, it is important to consider whether the result is model dependent, although this should be investigated in detail as a future topic. Fig. 4 shows the recent results from some of the PMIP2 models (in PMIP2 database in April, 2006), which have summer cooling in the same domain as in Fig. 1 and Fig. 3, but a reduced total cooling (the LGM minus present day) with the assumption of a constant lapse rate using the topography in each model. Clear distinctive cooling over the ice sheet is still seen, while the strength of cooling depends on the model. HadCM3M2 has the strongest cooling, while CCSM has the weakest cooling over the ice sheet especially for the Fennoscandian ice sheet. The strength of of cooling over the ice sheet is not necessarily correlated with the global mean temperature. This could be partly due to the different albedo feedbacks and different cloud feedbacks, which largely determine the climate sensitivity in each model. Slightly different responses in atmospheric circulation such as stationary waves, or the position of storm tracks and ocean circulation, such as the response of meridional overturning in the North Atlantic or the position of Gulf Stream could also lead to the different cooling over the ice sheet in the four models (also see Braconnot et al., 2007; Hargreaves et al., 2007). Based on these GCM results we conclude there remains considerable uncertainty over the actual size of the albedo effect.

The precipitation over the ice sheets and its relation to temperature was studied in our previous paper (Yamagishi et al., 2005). Here we discuss the precipitation in four different GCMs from PMIP2. Figure 5 shows the annual precipitation change ratio in per cent. A prominent feature overall is the larger desertification effect in the inland of the ice sheet for 
(a) $\operatorname{CCSM}$

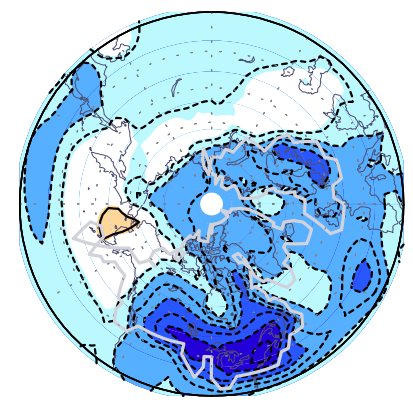

(b) $\operatorname{HadCM} 3 \mathrm{M} 2$

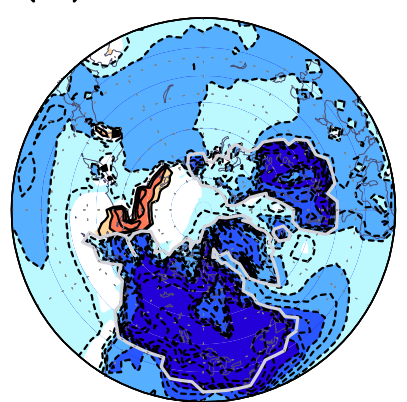

(c) IPSL

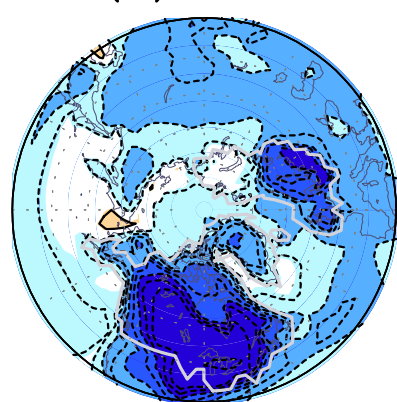

(d) MIROC3.2.2 ${ }^{\left[{ }^{\circ} \mathrm{C}\right]}$

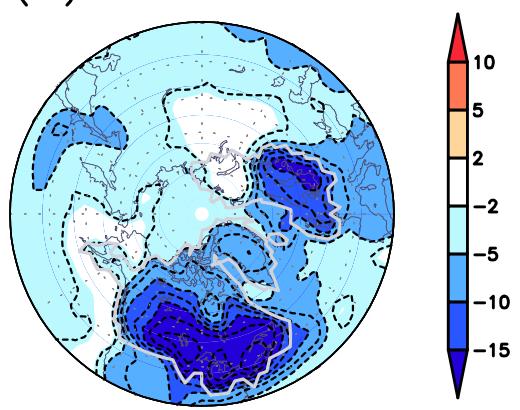

Fig. 4. Change in summer surface air temperature for a subset of PMIP2 simulations: (a) CCSM, (b) HadCM3M2, (c) IPSL, (d) MIROC3.2. The lapse rate effect is extracted by assuming the lapse rate $=5 \mathrm{~K} \mathrm{~km}^{-1}$ for each modelled ice sheet topography.

\section{(a) $\operatorname{CCSM}$}

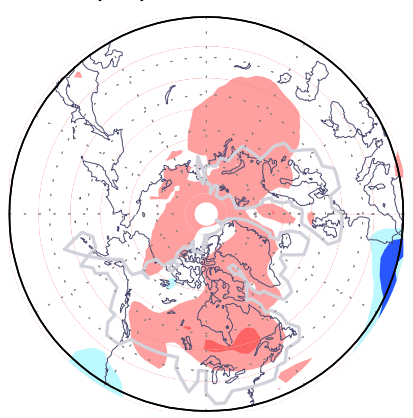

(b) $\operatorname{HadCM} 3 \mathrm{M} 2$

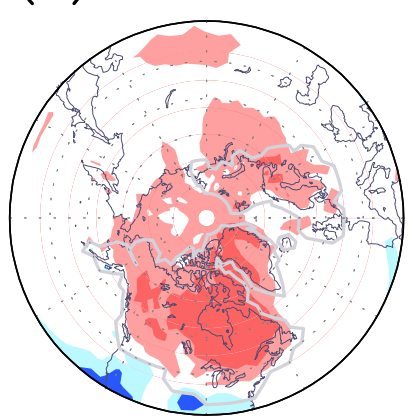

(c) IPSL

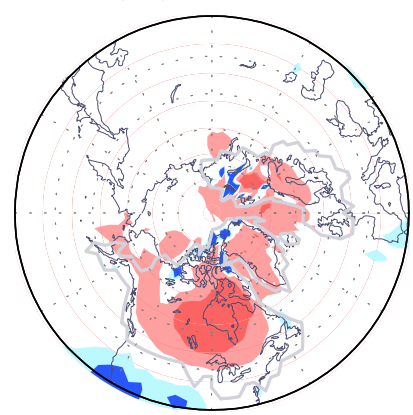

(d) MIROC3.2.2

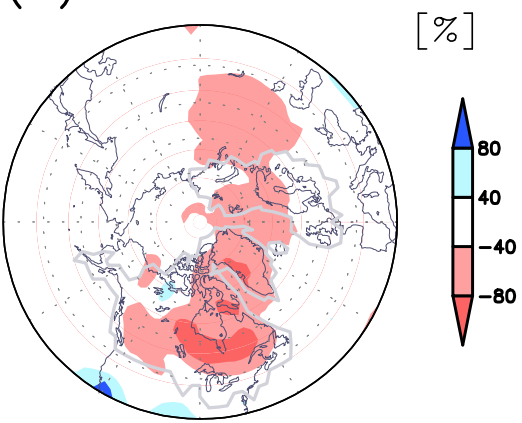

Fig. 5. Ratio of annual precipitation change in per cent for PMIP2 models: (a) CCSM, (b) HadCM3M2, (c) IPSL (d) MIROC3.2 by using (LGM-CTL)/CTL.

cooler temperature over the ice sheet, i.e., among the four, HadCM3M2 is the driest (as it was the coolest) over the ice sheets and CCSM is the opposite, which is not necessarily correlated with the global feature such as the climate sensitivity (see Braconnot et al., 2007). All the models show a large precipitation decrease of about $80 \%$ over the Laurentide ice sheet, and about 60 to $80 \%$ over the Greenland ice sheet which is very consistent with ice core data on accumulation (Dansgaard et al., 1993; Yamagishi et al., 2005). What is not seen in these PMIP2 runs is the precipitation increase in the south-east margin of the Laurentide ice sheet at the LGM, which was discussed in Kageyama and Valdes (2000) and Yamagishi et al. (2005). This demonstrates that a resolution of 2.5 to 3 degree in latitude and longitude in the used GCMs is not good enough to produce an accurate input for precipitation for the south-east margin of the ice sheet for driving ice sheet models.

\subsection{Response of climate to orbital parameters and $\mathrm{CO}_{2}$}

Response of the climate to the orbital parameters and $\mathrm{CO}_{2}$ were examined in both cases with the ice sheet and without the ice sheet as in Table 1. Figs. 6a and c show an example of response to precessional condition by $\mathrm{M} 21 \mathrm{O} 2 \mathrm{C} 1$ minus M21O1C1, and Figs. $6 \mathrm{~b}$ and d show the response to change in $\mathrm{CO}_{2}$ by $\mathrm{M} 21 \mathrm{O} 1 \mathrm{C} 2$ minus $\mathrm{M} 21 \mathrm{O} 1 \mathrm{C} 1$ for the response of 3 months temperature (June, July, August and December, January and February). In both cases there is a larger response over the land than over the ocean except over sea ice region. Also there is a larger response for the orbital effect than the $\mathrm{CO}_{2}$ effect in this model. Later the ice sheet model is driven by the orbital effect and $\mathrm{CO}_{2}$ effect based on this estimation over land in the Northern Hemisphere. Again the cloud feedback and water vapor feedback are included in the response, and this might result in a different sensitivity when the orbital parameter and $\mathrm{CO}_{2}$ as well as the ice sheet change.

Non-linear effects from the combined orbital, $\mathrm{CO}_{2}$ and even the ice sheet effect were checked by examining other combinations as in Table 1. Although this will be discussed 


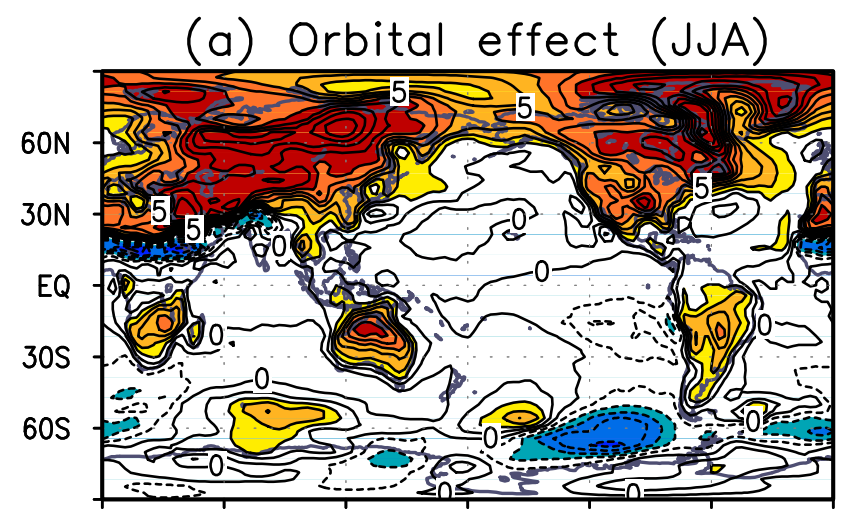

(c) Orbital effect (DJF)

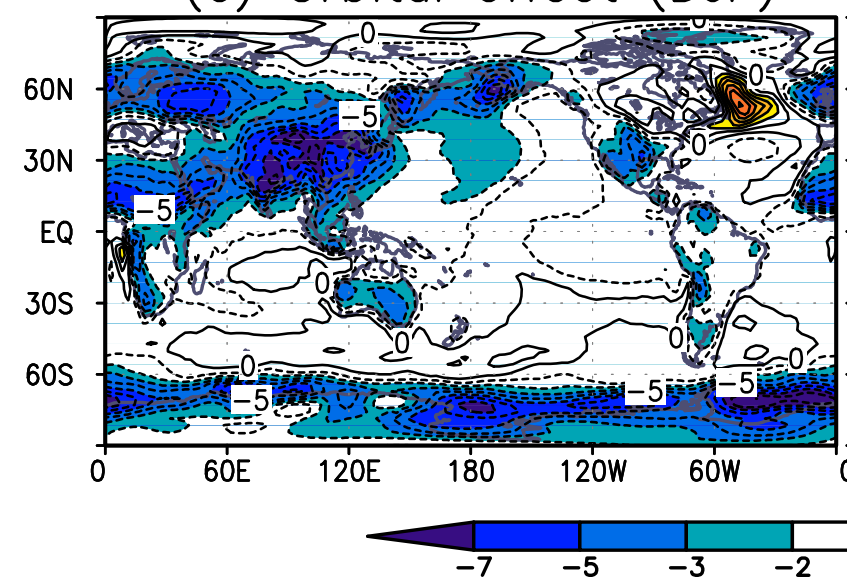

(b) $\mathrm{CO}_{2}$ effect (JJA)

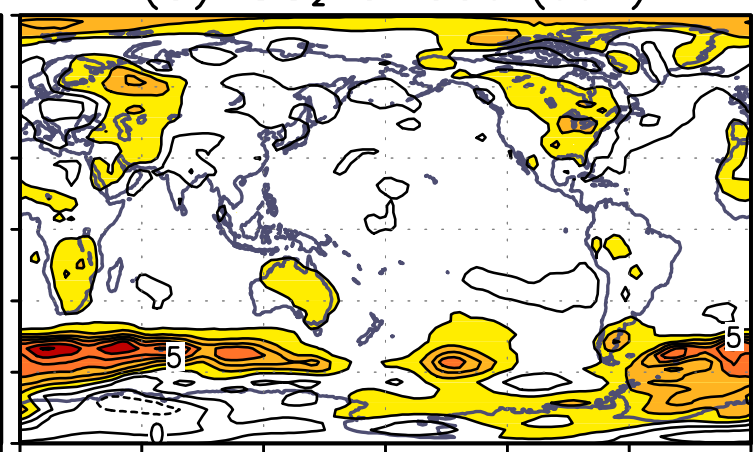

(d) $\mathrm{CO}_{2}$ effect (DJF)
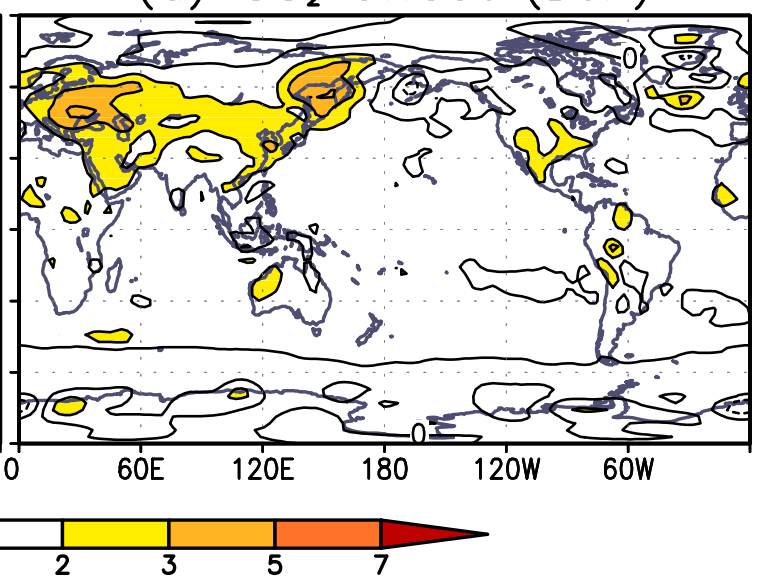

Fig. 6. Difference in the surface temperature of summer (mean of June, July, and August) and winter (mean of December, January, February) for two cases of different (a), (c) Orbital effect and (b), (d) $\mathrm{CO}_{2}$ effect. Contour interval is $1^{\circ} \mathrm{C}$.

in more detail in a separate paper in future, the nonlinear effect was at most about $15 \%$ and no more than $20 \%$. Since, in general, the response is larger under cooler climate, the same change in $\mathrm{CO}_{2}$ or the orbital parameters can result in a slightly larger response with the ice sheet than without ice sheet. This should be taken into account in future, although omitted in Sect. 4 for simplicity.

\section{Ice sheet model experiments with GCM information}

The main focus of this section is to use the GCM results obtained in the previous section to force an ice sheet model for one glacial-interglacial cycle. Instead of using geographically distributed information, we use spatially uniform climatic input for the ice sheet model in the first step. The system is driven by a combination of orbital (Milankovitch) and $\mathrm{CO}_{2}$ forcings. We investigate whether the main features of glacial-interglacial cycles, such as the fast retreat of the ice sheets at the termination and the geographical pattern is properly simulated at key periods such as the LGM. Several runs are performed to investigate the sensitivity of the results to the parameters in realistic ranges of values.

\subsection{Experimental set-up of the ice sheet model}

\subsubsection{Standard experimental setup}

The IcIES ice sheet model described in Sect. 2.2 is used for the glacial-interglacial experiments. The forcing scenarios are incorporated into the terms $\Delta T_{\mathrm{CO}_{2}}$ and $\Delta T_{\text {insol }}$ in Eq. (5), which are prescribed without feedback from ice-sheets.

The time series of $\mathrm{CO}_{2}$ concentration obtained from the Vostok ice core (Petit et al., 1999) is applied. Changes in temperature due to change in $\mathrm{CO}_{2}$ concentration are parameterized using the following relation:

$$
\Delta T_{\mathrm{CO}_{2}}=\frac{\frac{C}{240}-1}{\frac{280}{240}-1} \times 1.088-1.81584
$$

where $C$ is the atmospheric concentration of $\mathrm{CO}_{2}$ in ppm. The relation and the coefficients are derived from the AGCM experiments in the present paper. 

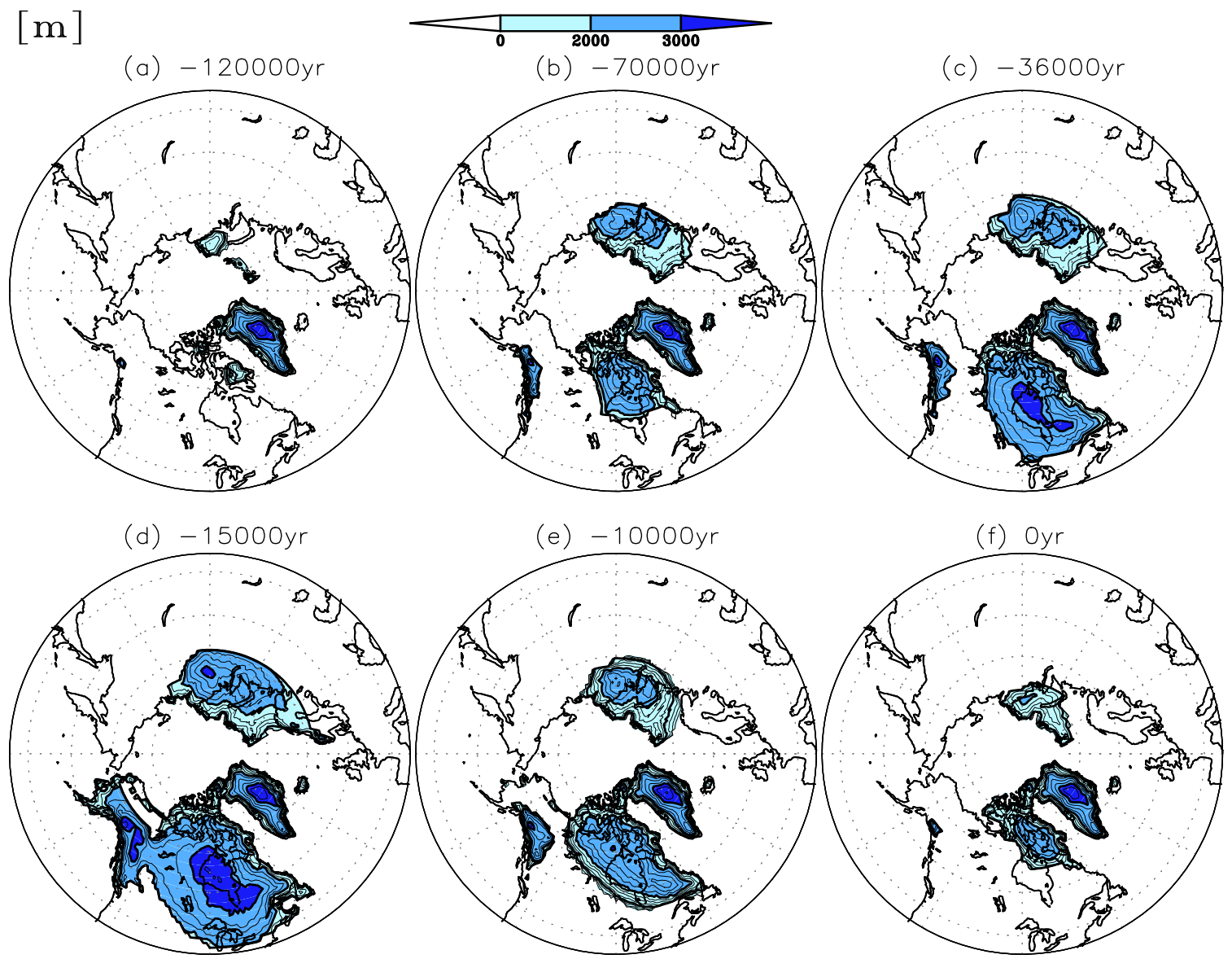

Fig. 7. Ice sheet distribution at different stages at (a) $120 \mathrm{ka}$, (b) $70 \mathrm{ka}$, (c) $36 \mathrm{ka}$, (d) $15 \mathrm{ka}$, (e) $10 \mathrm{ka}$, (f) $0 \mathrm{ka}$. Contour intervals are $250 \mathrm{~m}$ (thin lines) and $1000 \mathrm{~m}$ (thick lines). The volume of each ice sheet in terms of sea level contribution is (a) $-6.278 \mathrm{~m},(\mathrm{~b})-51.643 \mathrm{~m}$, (c) $-90.253 \mathrm{~m}$, (d) $-137.827 \mathrm{~m}$, (e) $-77.167 \mathrm{~m}$, (f) $-27.095 \mathrm{~m}$.

To obtain the effect of changes in insolation, we first compute time series of July insolation at $65^{\circ} \mathrm{N}$, using the orbital parameters of Berger (1978). Then change in temperature due to change in the insolation is parameterized using the following relation estimated from our GCM runs in the previous section:

$$
\Delta T_{\text {insol }}=\frac{Q-440}{480-440} \times 3.25+1.0757,
$$

where $Q$ is the insolation in $\mathrm{W} \mathrm{m}^{-2}$. The relation and the coefficients are derived from the AGCM experiments in the present paper, as Eq. (6).

The other terms in Eq. (5) are also derived from the AGCM experiments. We assume in this study that the non-linearity $\Delta T_{\text {nonlinear }}$ is zero, although it can be up to $20 \%$ as explained in Sect. 3.3. This contribution will be included in the following ice sheet effect.

We divide the ice-sheet effect $\Delta T_{\text {ice }}$ on the surface temperature in two terms as follows:

$$
\Delta T_{\text {ice }}=\Delta T_{\text {elv }}+\Delta T_{\text {area }}
$$

where $\Delta T_{\text {elv }}$ the effect of change in surface elevation, and $\Delta T_{\text {area }}$ denotes the effect of albedo change.

The lapse-rate effect $\Delta T_{\text {elv }}$ is a function of ice-sheet elevation as follows:

$$
\Delta T_{\mathrm{elv}}=\lambda\left(h-h_{\mathrm{ref}}\right),
$$

where $h_{\text {ref }}$ is the reference topography elevation (the present observed topography) and $\lambda$ is the lapse rate.

The albedo effect $\Delta T_{\text {area }}$ is assumed to be a function of the simulated ice-sheet area $A_{\text {rea }}$,

$$
\Delta T_{\text {area }}=\max \left[\Delta T_{\text {area }}^{\mathrm{min}}, \Delta T_{\text {area }}^{0}+\gamma_{\text {area }}^{\mathrm{T}} \times A_{\text {rea }}\right] .
$$

We assume a linear dependence on temperature by coefficients $\Delta T_{\text {area }}^{0}$, offset of albedo effect and $\gamma_{\text {area }}^{\mathrm{T}}$, dependence (linear gradient) of albedo effect on the ice-sheet cover, assuming a minimum value $\Delta T_{\text {area }}^{\text {min }}$.

For the choice of the parameters in Eqs. (9) and (10), we perform sensitivity experiments, which will be explained in Sect. 4.1.2. 
Table 3. Parameter choices for ice-sheet model experiments.

\begin{tabular}{lcccll}
\hline Parameter & A & B & C & Unit & Symbol \\
\hline Lapse rate & -4.0 & -5.0 & -6.0 & $\mathrm{~K} \mathrm{~km}^{-1}$ & $\lambda$ in Eq. (9) \\
Desertification rate & 0.01 & 0.022 & 0.04 & - & $d_{0}$ in Eq. (11) \\
Albedo effect & -3.7 & -4.7 & -5.7 & $10^{-13} \mathrm{~K} \mathrm{~m}^{-2}$ & $\gamma_{\text {area }}^{\mathrm{T}}$ in Eq. (10) \\
\hline
\end{tabular}

For the reference temperature distribution, we apply the climatology of present day, obtained from ERA40 (reanalysis of the European Centre for Medium-Range Weather Forecast).

In addition, coefficient $d_{\mathrm{P}}$ in Eq. (4) is also derived from the AGCM experiments in Yamagishi et al. (2005). Contrary to Marshall et al. (2002), the coefficient $d_{\mathrm{P}}$ is assumed as a function of ice-sheet area as follows:

$$
d_{\mathrm{P}}=\min \left[d_{0} \times \frac{A_{\text {rea }}}{1.4 \times 10^{13}}, 1.0\right],
$$

where $A_{\text {rea }}$ is the area covered by simulated ice-sheet in $\mathrm{m}^{2}$ unit. The reference area $1.4 \times 10^{13} \mathrm{~m}^{2}$ approximately corresponds to that of the Laurentide ice sheet at the last glacial maximum of Peltier (1994).

The total model domain in this study is divided into four parts: North America, Eurasia, Greenland and elsewhere. $A_{\text {rea }}$ used in Eqs. (10) and (11), is computed in each part as the sum of the area of all grid cells where ice exists.

The time integration is performed for the last 120 thousand years in the present paper. For the initial conditions, we take a situation which is close to the present day condition, as shown in Fig. 7a from one of our experiments of longer time integration. Several initial conditions at $130 \mathrm{ka} \mathrm{BP}$ and before are examined (not shown). It is found, however, that the difference in the initial conditions is small and does not affect the results for the last $120 \mathrm{ka}$.

\subsubsection{Experimental set-up of the sensitivity studies}

In order to study influences from uncertain processes on the response of the ice sheet to climate change, several sensitivity experiments were performed. In this paper, sensitivity experiments to the choice of the lapse-rate, albedo effect and the desertification rate are shown. The parameters are summarized in Table 3 .

The lapse rate $\lambda$ in Eq. (9) is set at $-5.0 \mathrm{~K} \mathrm{~km}^{-1}$ as the standard value, but sensitivity experiments with different values such as $-4.0 \mathrm{~K} \mathrm{~km}^{-1}$ and $-6.0 \mathrm{~K} \mathrm{~km}^{-1}$ were carried out.

The desertification rate parameter, corresponding to $d_{0}$ in Eq. (11), is set at 0.022 as the standard value, which is obtained from Yamagishi et al. (2005). We also performed sensitivity studies with a smaller $d_{0}=0.01$ and a larger $d_{0}=0.04$.

In the standard configuration, coefficients in Eq. (10) are set as $\Delta T_{\text {area }}^{\min }=-13.0 \mathrm{~K}, \Delta T_{0}^{\mathrm{min}}=-4.0 \mathrm{~K}$ and $\gamma_{\text {area }}^{\mathrm{T}}=-4.7 \times 10^{-13} \mathrm{~K} \mathrm{~m}^{-2}$. We performed sensitivity studies on the temperature-dependence coefficient $\gamma_{\text {area }}^{\mathrm{T}}$ with two cases, $\gamma_{\text {area }}^{\mathrm{T}}=-3.7 \times 10^{-13} \mathrm{~K} \mathrm{~m}^{-2}$ and $\gamma_{\text {area }}^{\mathrm{T}}=-5.7 \times 10^{-13} \mathrm{~K} \mathrm{~m}^{-2}$. Those values are obtained from the AGCM experiments M21nice, M21flat and M12flat (see Table 1), with taking into account the variance.

\subsection{Glacial-interglacial experimental results}

As for the standard experiment, the result of the altitude distribution of the ice sheet is shown in Fig. 7 for various time periods, and the time series are shown in Fig. 8 by black thick lines in (4) and (5), together with (1) insolation (2) $\mathrm{CO}_{2}$ change and (3) proxy of sea level. The gradual growth and the fast retreat of the ice sheets is the characteristics, known as "sawtooth" shape, similar to the proxy data such as SPECMAP (Imbrie et al., 1989; McIntyre et al., 1989; Imbrie et al., 1993). The maximum volume of about 138 meter of sea level equivalent at $15 \mathrm{ka} \mathrm{BP}$ is somewhat larger than what is discussed in literature (e.g. Clark and Mix, 2002; Peltier, 2004), but the geographical pattern is quite well simulated as in Fig. 7d except several points such as: (1) the remnant ice at $0 \mathrm{kaBP},(2)$ insufficient growth rate at ice age inception between $120 \mathrm{ka} \mathrm{BP}$ and $110 \mathrm{ka} \mathrm{BP},(3)$ overestimated volume of the ice sheet and the delay of timing of the glacial maximum and (4) overestimation of ice extent of the Eurasian ice sheet. These will be discussed in the next section.

The experiment captures well the relatively larger Laurentide ice sheet and somewhat smaller Eurasian ice sheet, and the merging of the ice sheet over Labrador and the Rockies around $21 \mathrm{ka}$. The Laurentide ice sheet splits before $10 \mathrm{ka} \mathrm{BP}$ but the termination is not as complete as that observed at present day, and some remnant ice is left over in the Canadian archipelago and in the Kara Sea. The maximum of the ice volume is somewhat later than reconstructed at $21 \mathrm{ka}$, which is the time normally considered as representing the LGM.

Figure 8 shows the sensitivity of the ice volume to the parameters of the albedo effect, temperature lapse rate, and desertification rate. Larger lapse rate or larger albedo effect or smaller desertification effect result in larger ice sheets at about $20 \mathrm{ka} \mathrm{BP}$ at the maximum volume stage. In almost all experiments the inception and termination of ice age occur. In almost all cases, the larger ice sheet at the glacial maximum end with a larger ice left at the $0 \mathrm{kaBP}$ after termination. Extreme combinations of these parameters results in extremely large ice sheets, with volumes up to $300 \mathrm{~m}$ in sea 


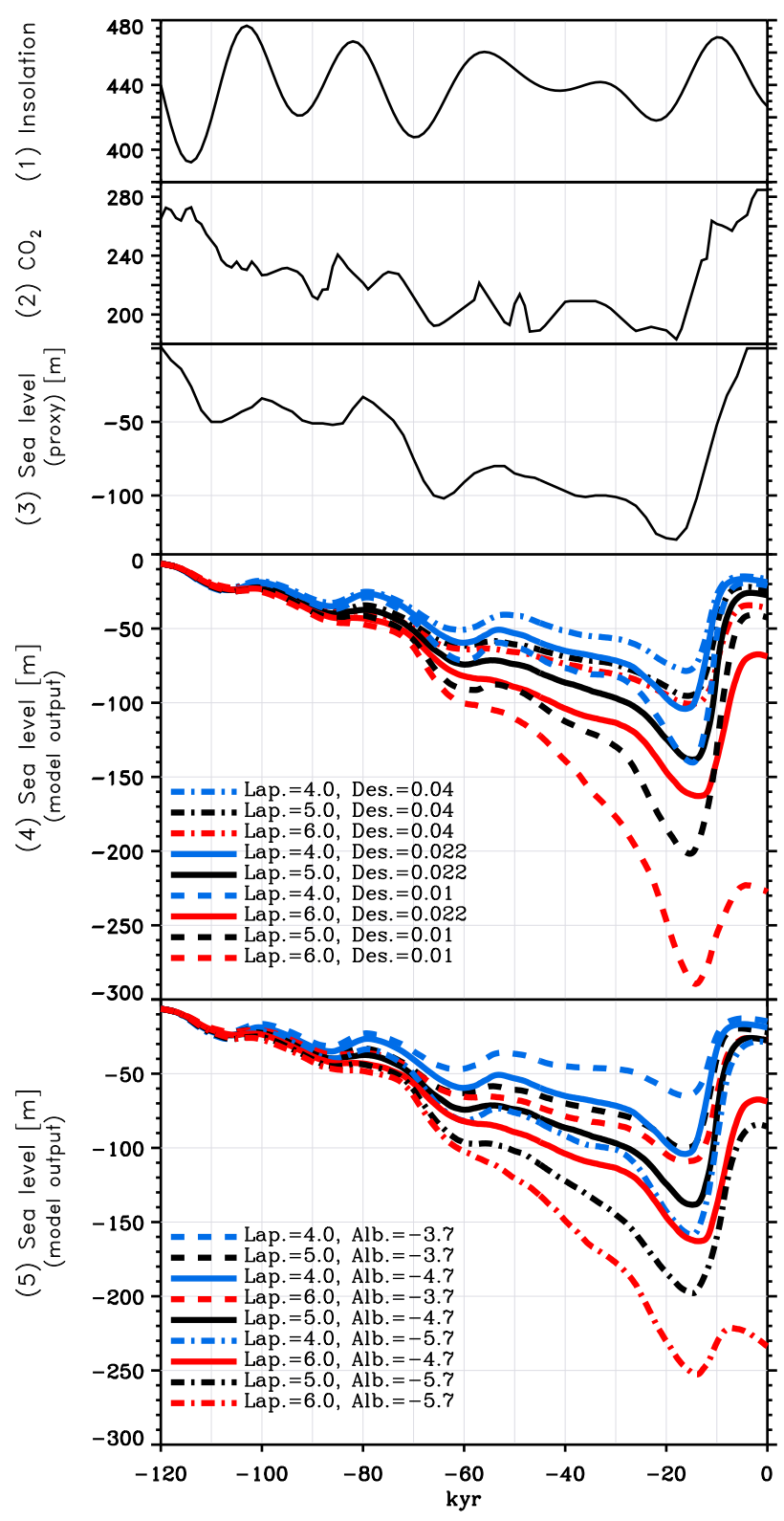

Fig. 8. Time series for 120000 years of the forcing (1) insolation and (2) $\mathrm{CO}_{2},(3)$ proxy of the ice sheet size equivalent to sea level and (4), (5) Simulated changes in ice-sheet volume in sea level equivalent by experiments under different conditions depending on the lapse rate, albedo-effect and desertification rate parameter. (3) Observation taken from SPECMAP (Imbrie et al., 1989; McIntyre et al., 1989; http://www.ngdc.noaa.gov/mgg/geology/specmap. $\mathrm{html}$ ), and converted to sea level drop assuming a maximum level of 130 meter drop. In (4) and (5), Lapse rate, Albedo effect parameter and desertification parameter are changed. Lap. is the lapse rate parameter in $\mathrm{K} \mathrm{km}^{-1}$ corresponding to $\lambda$ in Eq. (9); Des. is the desertification rate parameter corresponding to $d_{0}$ in Eq. (11); Alb. is the albedo effect parameter in $10^{-13} \mathrm{~K} \mathrm{~m}^{-2}$ corresponding to $\gamma_{\text {area }}^{\mathrm{T}}$ in Eq. (10). level equivalent. These results demonstrate the importance of careful treatment of parameters related to ice sheet and atmosphere interactions.

\subsection{Discussion}

Although the overall features of the ice sheets are well simulated, some detailed features are not captured correctly, as described in the previous section. These features may come from deficiencies or simplifications or assumptions in the model and experimental setup, such as the omission of possible non-linear effects or assumption of a constant lapse rate or the too simple relation between the albedo feedback and ice sheet size. Additionally the representation of sub-grid scale phenomena of ice dynamics, omission of feedbacks due to atmospheric circulation such as stationary wave feedback or storm track feedback and other feedbacks from ocean or vegetation should also be considered for future investigation.

Uncertainties in ice-sheet modeling such as basal-sliding parameterization, geothermal heat flux, isostatic response and so on should be investigated as suggested in Marshall et al. (2002); Charbit et al. (2002); Zweck and Huybrechts (2005). Also, several studies have reported that there are significant errors in the simulated ice thickness near the margin (e.g., Huybrechts et al., 1996). Van den Berg et al. (2006) have shown that these errors are enhanced by the feedback between the surface mass balance and height. They also showed that these errors strongly influence the time scale of the simulated volume changes. The implementation of an improved scheme to reduce the error at the ice margin (Saito et al., 2007) is one of the next steps for the present study. Moreover, the bedrock treatment should be improved in future since we think it is over-simplified in our method, with an equilibrium assumed for the present day. The influence of the above uncertainties on the results of the present paper will be addressed in future research.

\section{Summary and conclusions}

In this paper, the analysis was made of feedback processes between the ice sheets and the atmosphere using results from numerical experiments with a high resolution GCM run under different conditions at the Last Glacial Maximum. Among the processes analyzed, the ice albedo feedback, the elevation-mass balance feedback and the desertification effect over the ice sheets were found to be the dominant influences on the ice-sheet mass balance. A value of $5^{\circ} \mathrm{C} \mathrm{km}^{-1}$ is proposed for the lapse rate over the ice sheet. This is a smaller value than proposed by previous studies. Within a plausible range of parameters related to these processes, the ice sheet response to the orbital parameters and atmospheric $\mathrm{CO}_{2}$ concentration for the last glacial/interglacial cycle was simulated in terms of both ice volume and geographical distribution, using a three-dimensional ice-sheet model. 
Since the cooling and the drop in precipitation over the ice sheets depends on the parameterizations in the models, a careful treatment of the processes related to atmosphere-ice sheet feedback is essential for the simulation of the ice sheet changes during an ice age cycle.

Acknowledgements. We thank H. Blatter, L. Tarasov, P. Bracconot, J. Hargreaves and an anonymous reviewer for their critical comments on the manuscript; S. Manabe for his support on the work; T. Nishimura, T. Yamagishi and R. Ohgaito for their technical support and valuable discussions. We acknowledge the international modelling groups for providing their data for analysis, the Laboratoire des Sciences du Climat et de l'Environment (LSCE) for collecting the model data and D. Peltier for providing the ice sheet reconstruction, ICE-4G and ICE-5G. The model simulations were performed on an NEC SX-5 and SX-8 at FRCGC, JAMSTEC, Yokohama. The research was supported by JSPS Grant-in-Aid for Scientific Research (B) no. 16340136.

Edited by: P. Braconnot

\section{References}

Berger, A.: Long-term variations of caloric insolation resulting from the Earth's orbital elements, Quat. Res., 9, 139-167, 1978.

Berger, A., Loutre, M. F., and Gallée, H.: Sensitivity of the LLN climate model to the astronomical and $\mathrm{CO}_{2}$ forcings over the last 200 ky, Climate Dyn., 14, 615-629, 1998.

Braconnot, P., Otto-Bliesner, B., Harrison, S., Joussaume, S., Peterchmitt, J.-Y., Abe-Ouchi, A., Crucifix, M., Driesschaert, E., Fichefet, T., Hewitt, C. D., Kageyama, M., Kitoh, A., Laîné, A., Loutre, M.-F., Marti, O., Merkel, U., Ramstein, G., Valdes, P., Weber, L., Yu, Y., and Zhao, Y.: Results of PMIP2 coupled simulations of the mid-Holocene and Last Glacial Maximum Part 1: experiments and large-scale features, Clim. Past, 3, 261-277, 2007 ,

http://www.clim-past.net/3/261/2007/.

Braithwaite, R. J.: Positive degree-day factors for ablation on the Greenland ice sheet studied by energy-balance modelling, J. Glaciol., 41, 153-160, 1995.

Braithwaite, R. J. and Olesen, O. B.: Calculation of glacier ablation from air temperature, West Greenland, in: Glacier fluctuations and climatic change, edited by: Oerlemans, J., Dordrecht, Kluwer Academic Publishers, 219-233, 1989.

Broccoli, A. J. and Manabe, S.: The influence of continental ice, atmospheric $\mathrm{CO}_{2}$ and land albedo on the climate of the last glacial maximum, Climate Dyn., 1, 87-99, 1987.

Charbit, S., Ritz, C., and Ramstein, G.: Simulations of Northern Hemisphere ice-sheet retreat: sensitivity to physical mechanisms involved during the Last Deglaciation, Quat. Sci. Rev., 21, $243-$ 265, 2002.

Charbit, S., Kageyama, M., Roche, D., Ritz, C., and Ramstein, G.: Investigating the mechanisms leading to the deglaciation of past continental northern hemisphere ice sheets with the CLIMBERGREMLINS coupled model, Global Planet. Change, 48, 253 273, doi:10.1016/j.gloplacha.2005.01.002, 2005.

Clark, P. U. and Mix, A. C.: Ice sheets and sea level of the Last Glacial Maximum, Quat. Sci. Rev., 21, 1-7, 2002.
CLIMAP: Seasonal reconstructions of the Earth's surface at the last glacial maximum, no. MC-36 in Map Chart Series, Geological Society of America, Boulder, Colorado, 1981.

Cook, K. H. and Held, I. M.: Stationary waves of the ice age climate, J. Climate, 1, 807-819, 1998.

Dansgaard, W., Johnsen, S. J., Clausen, H. B., Dahl-Jensen, D., Gudestrup, N. S., Hammer, C. U., Hvidberg, C. S., Steffensen, J. P., Sveinbjörnsdottir, A. E., Jouzel, J., and Bond, G.: Evidence for general instability of past climate from a 250-kyr ice-core record, Nature, 364, 218-220, 1993.

Deblonde, G. and Peltier, W. R.: Simulations of Continental Ice Sheet Growth Over the Last Glacial-Interglacial Cycle: Experiments With a One-Level Seasonal Energy Balance Model Including Realistic Geography, J. Geophys. Res., 96, 9189-9215, 1991.

Dyke, A. S., Andrews, J. T., Clark, P. U., England, J. H., Miller, G. H., Shaw, J., and Veillette, J. J.: The Laurentide and Innuitian ice sheets during the Last Glacial Maximum, Quat. Sci. Rev., 21, 9-31, 2002.

Emori, S., Nozawa, T., Abe-Ouchi, A., Numaguti, A., Kimoto, M., and Nakajima, T.: Coupled ocean-atmosphere model experiments of future climate change with an explicit representation of sulfate aerosol scattering, J. Met. Soc. Japan, 77, 1299-1307, 1999.

Fabre, A., Ritz, C., and Ramstein, G.: Modelling of Last Glacial Maximum ice sheets using different accumulation parameterizations, Ann. Glaciol., 24, 223-228, 1997.

Fabre, A., Ramstein, G., Ritz, C., Pinot, S., and Fournier, N.: Coupling an AGCM with an ISM to investigate the ice sheets mass balance at the Last Glacial Maximum, Geophys. Res. Lett., 25, 531-534, 1998.

Felzer, B., Oglesby, R. J., III, T. W., and Hyman, D. E.: Sensitivity of a general circulation model to changes in northern hemisphere ice sheets, J. Geophys. Res., 101, $19077-19092,1996$.

Greve, R.: Application of a polythermal three-dimensional ice sheet model to the Greenland ice sheet: response to steady-state and transient climate scenarios, J. Climate, 10, 901-918, 1997.

Greve, R.: On the response of the Greenland ice sheet to greenhouse climate change, Climate Change, 46, 289-303, 2000.

Greve, R., Wyrwoll, K.-H., and Eisenhauer, A.: Deglaciation of the Northern hemisphere at the onset of the Eemian and Holocene, Ann. Glaciol., 28, 1-8, 1999.

Greve, R., Wang, Y., and Mügge, B.: Comparison of numerical schemes for the solution of the advective age equation in ice sheets, Ann. Glaciol., 35, 487-494, 2002.

Hansen, J., Lacis, A., Rind, D., Russell, G., Stone, P., Fung, I., Ruedy, R., and Lerner, J.: Climate sensitivity: Analysis of feedback mechanisms, in: Climate Processes and Climate Sensitivity, AGU Geophysical Monograph 29, Maurice Ewing Vol. 5, edited by: Hansen, J. E. and Takahashi, T., American Geophysical Union, 130-163, 1984.

Hargreaves, J. C., Abe-Ouchi, A., and Annan, J. D.: Linking glacial and future climates through an ensemble of GCM simulations, Clim. Past, 3, 77-87, 2007, http://www.clim-past.net/3/77/2007/.

Hays, J. D., Imbrie, J., and Shackleton, N. J.: Variations in the Earth's orbit: pacemaker of the ice ages, Science, 194, 11211132, 1976.

Hindmarsh, R. C. A.: Notes on basic glaciological computational 
methods and algorithms, in: Continuum Mechanics and Applications in Geophysics and the Environment, edited by: Straughan, B., Greve, R., Ehrentraut, H., and Wang, Y., Springer-Verlag, Berlin, 222-249, 2001.

Hindmarsh, R. C. A. and Payne, A. J.: Time-step limits for stable solutions of the ice-sheet equation, Ann. Glaciol., 23, 74-85, 1996.

Hutter, K.: Theoretical glaciology; material science of ice and the mechanics of glaciers and ice sheets, Dordrecht, etc., D. Reidel Publishing company/Tokyo, 1983.

Huybrechts, P. and T'siobbel, S.: Thermomechanical modelling of northern Hemispher ice sheets with a two-level mass-balance parameterization, Ann. Glaciol., 21, 111-116, 1995.

Huybrechts, P. and T'siobbel, S.: A three-dimensional climate-icesheet model applied to the Last Glacial Maximum, Ann. Glaciol., 25, 333-339, 1997.

Huybrechts, P., Letréguilly, A., and Reeh, N.: The Greenland ice sheet and greenhouse warming, Palaeogeography, Palaeoclimatology, Palaeoecology, 89, 399-412, 1991.

Huybrechts, P., Payne, T., and The EISMINT Intercomparison group: The EISMINT benchmarks for testing ice-sheet models, Ann. Glaciol., 23, 1-12, 1996.

Huybrechts, P., Janssens, I., Poncin, C., and Fichefet, T.: The response of the Greenland ice sheet to climate changes in the 21st century by interactive coupling of an AOGCM with a thermomechanical ice-sheet model, Ann. Glaciol., 35, 409-415, 2002.

Imbrie, J., McIntyre, A., and Mix, A. C.: Oceanic Response to Orbital Forcing in the Late Quaternary: Observational and Experimental Strategies, in: Climate and Geosciences, A Challenge for Science and Society in the 21st Century, edited by: Berger, A., Schneider, S. H., and Duplessy, J.-C., D. Reidel Publishing Company, 1989.

Imbrie, J., Berger, A., Boyle, E. A., Clemens, S. C., Duffy, A., Howard, W. R., Kukla, G., Kutzback, J., Martinson, D. G., McIntyre, A., Mix, A. C., Molfino, B., Morley, J. J., Peterson, L. C., Pisias, N. G., Prell, W. L., Raymo, M. E., Shackleton, N. J., and Toggweiler, J. R.: On the structure and origin of major glaciation cycles. 2. The 100,000-year cycle, Paleoceanography, 8, 699735, 1993.

Jost, A., Lunt, M., Kageyama, M., Abe-Ouchi, A., Peyron, O., Valdes, P. J., and Ramstein, G.: High resolution simulations of the last glacial maximum climate over Europe: a solution to discrepancies with continental paleoclimatic reconstructions?, Climate Dyn., 24, 577-590, 2005.

Joussaume, S. and Taylor, K.: Status of the paleoclimate modeling intercomparison project (PMIP), in: WCRP-2, First International AMIP Scientific Conference, 15-19 May 1995, Monterey, CA. Proceedings, Geneva, World Meteorological Organisation. World Climate Research Programme, 415-430, 1995.

K-1 model developers: K-1 Coupled GCM (MIROC) Description, K-1 technical report 1, Center for Climate System Reserach, edited by: Hiroyasu Hasumi and Seita Emori, 2004.

Kageyama, M. and Valdes, P. J.: Impact of the North American ice-sheet orography on the Last Glacial Maximum eddies and snowfall, Geophys. Res. Lett., 27, 1515-1518, 2000.

Krinner, G. and Genthon, C.: Altitude dependence of the ice sheet surface climate, Geophys. Res. Lett., 26, 2227-2230, 1999.

Manabe, S. and Broccoli, A. J.: The influence of continental ice sheets on the climate of an ice age, J. Geophys. Res., 90, 2167-
2190, 1985.

Marshall, S. J. and Clark, P. U.: Basal temperature evolution of North American ice sheets and implications for the 100-kyr cycle, Geophys. Res. Lett., 29, 67, 2002.

Marshall, S. J., Tarasov, L., Clarke, G. K. C., and Peltier, W. R.: Glaciological reconstruction of the Laurentide ice sheet: physical processes and modelling challenges, Can. J. Earth Sci., 37, 769793, 2000.

Marshall, S. J., James, T. S., and Clarke, G. K. C.: North American Ice Sheet reconstructions at the Last Glacial Maximum, Quat. Sci. Rev., 21, 175-192, 2002.

Marsiat, I.: Simulation of the Northern Hemisphere continental ice sheets over the last glacial interglacial cycle: experiments with a latitude-longitude vertically integrated ice sheet model coupled to a zonally averaged climate model, Paleoclimates, 1, 59-98, 1994.

McIntyre, A., Ruddiman, W. F., Karlin, K., and Mix, A. C.: Surface water response of the equatorial Atlantic Ocean to orbital forcing, Paleoceanography, 4, 19-55, 1989.

Milankovitch, M.: Mathematische Klimalehre und Astronomishce Theorie der Klimaschwankungen, Gebruder Borntreger, Berlin, 1930.

Numaguti, A., Takahashi, T., Nakajima, T., and Sumi., A.: Description of CCSR/NIES atmospheric general circulation model, in: CGER's Supercomputer Monograph Report, vol. 3, Tokyo, National Institute for Environmental Studies. Center for Global Environmental Research, 1997.

Ohmura, A.: Physical Basis for the Temperature-Based Melt-Index Method, J. Appl. Meteorol., 40, 753-761, 2001.

Paillard, D.: The timing of Pleistocene glaciations from a simple multiple-state climate model, Nature, 391, 378-381, 1998.

Paillard, D.: Glacial cycles: toward a new paradigm, Rev. Geophys., 39, 325-346, 2001.

Paillard, D. and Parrenin, F.: The Antarctic ice sheet and the triggering of deglaciations, Earth Planet. Sci. Lett., 227, 263-271, 2004.

Payne, A. J.: A thermomechanical model of ice flow in West Antarctica, Climate Dyn., 15, 115-125, 1999.

Peltier, W. R.: Ice Age Paleotopography, Science, 265, 195-201, 1994.

Peltier, W. R.: Global Glacial Isostasy and the Surface of the IceAge Earth: The ICE-5G(VM2) Model and GRACE, Annu. Rev. Earth Planet. Sci., 32, 111-149, 2004.

Petit, J. R., Jouzel, J., Raynaud, D., Barkov, N. I., Barnola, J.-M., Basile, I., Bender, M., Chappellaz, J., Davis, M., Delayque, G., Delmotte, M., Kotlyakov, V. M., Legrand, M., Lipenkov, V. Y., Lorius, C., Pépin, L., Ritz, C., Saltzman, E., and Stievenard, M.: Climate and atmospheric history of the past 420,000 years from the Vostok ice core, Antarctica, Nature, 399, 429-436, 1999.

Pollard, D. and PMIP Participating Groups: Comparisons of icesheet surface mass budgets from Paleoclimate Modeling Intercomparison Project (PMIP) simulations, Global Planet. Change, 24, 79-106, 2000.

Ramstein, G., Fabre, A., Pinot, S., Ritz, C., and Joussaume, S.: Ice-sheet mass balance during the Last Glacial Maximum, Ann. Glaciol., 25, 145-152, 1997.

Raymo, M. E.: The timing of major climate terminations, Paleoceanography, 12, 577-585, 1997.

Raymo, M. E., Lisiecki, L. E., and Nisancioglu, K. H.: Plio- 
Pleistocene Ice Volume, Antarctica Climate, and the Global $\delta^{18} \mathrm{O}$ Record, Science, 313, 492-495, 2006.

Reeh, N.: Parameterization of melt rate and surface temperature on the Greenland ice sheet, Polarforschung, 59, 113-128, 1991.

Rind, D.: Components of the ice age circulation, J. Geophys. Res., 92, 4241-4281, 1987.

Ritz, C., Fabre, A., and Letréguilly, A.: Sensitivity of a Greenland ice sheet model to ice flow and ablation parameters: consequences for the evolution through the last climatic cycle, Climate Dyn., 13, 11-24, 1997.

Roe, G. H. and Lindzen, R. S.: The Mutual Interaction between Continental-Scale Ice Sheets and Atmospheric Stationary Waves., J. Climate, 14, 1450-1465, 2001.

Saito, F. and Abe-Ouchi, A.: Thermal structure of Dome Fuji and east Dronning Maud Land, Antarctica, simulated by a threedimensional ice-sheet model, Ann. Glaciol., 39, 433-438, 2004.

Saito, F. and Abe-Ouchi, A.: Sensitivity of Greenland ice sheet simulation to the numerical procedure employed for ice sheet dynamics, Ann. Glaciol., 42, 331-336, 2005.

Saito, F., Abe-Ouchi, A., and Blatter, H.: An improved numerical scheme to compute horizontal gradients at the ice-sheet margin: its effect on the simulated ice thickness and temperature, Ann. Glaciol., 46, 87-96, 2007.

Schlesinger, M. E. and Verbitsky, M.: Simulation of glacial onset with a coupled atmospheric general circulation/mixed-layer ocean-ice-sheet/asthenosphere model, Palaeoclimates - Data and Modelling, 2, 179-201, 1996.

Shinn, R. A. and Barron, E. J.: Climate Sensitivity to Continental Ice Sheet Size and Configuration, J. Climate, 2, 1517-1537, 1989.

Svendsen, J. I., Alexanderson, H., Astakhov, V. I., Demidov, I., Dowdeswell, J. A., Funder, S., Gataullin, V., Henriksen, M., Hjort, C., Houmark-Nielsen, M., Hubberten, H. W., Ingolfsson, O., Jakobsson, M., Kjaer, K. H., Larsen, E., Lokrantz, H., Lunkka, J. P., Lysa, A., Mangerud, J., Matiouchkov, A., Murray, A., Moller, P., Niessen, F., Nikolskaya, O., Polyak, L., Saarnisto, M., Siegert, C., Siegert, M. J., Spielhagen, R. F., and Stein, R.: Late quaternary ice sheet history of northern Eurasia, Quat. Sci. Rev., 23, 1229-1271, 2004.
Tarasov, L. and Peltier, W. R.: Terminating the 100 kyr ice age cycle, J. Geophys. Res., 102, 21 665-21 693, 1997a.

Tarasov, L. and Peltier, W. R.: A high-resolution model of the 100ka ice-age cycle, Ann. Glaciol., 25, 58-65, 1997b.

Tarasov, L. and Peltier, W.: Impact of thermomechanical ice sheet coupling on a model of the $100 \mathrm{kyr}$ ice age cycle, J. Geophys. Res., 104, 9517-9546, 1999.

Thompson, S. L. and Pollard, D.: Greenland and Antarctic Mass Balances for Present and Doubled Atmospheric $\mathrm{CO}_{2}$ from the GENESIS Version-2 Global Climate Model, J. Climate, 10, 871900, 1997.

van de Wal, R. S. W.: Mass-balance modelling of the Greenland ice sheet: a comparison of an energy-balance and a degree-day model, Ann. Glaciol., 23, 36-45, 1996.

van den Berg, J., van de Wal, R. S. W., and Oerlemans, J.: Effects of spatial discretization in ice-sheet modelling using the shallow-ice approximation, J. Glaciol., 52, 89-98, 2006.

Verbitsky, M. Y. and Oglesby, R. J.: The effect of Atmospheric carbon dioxide concentration on continental glaciation of the northern hemisphere, J. Geophys. Res., 97, 5895-5909, 1992.

Xie, P. and Arkin, P. A.: Analyses of global monthly precipitation using gauge observations, satellite estimates, and numerical model predictions, J. Climate, 9, 840-858, 1996.

Yamagishi, T., Abe-Ouchi, A., Saito, F., Segawa, T., and Nishimura, T.: Re-evaluation of paleo-accumulation parameterization over Northern Hemisphere ice sheets during the ice age examined with a high-resolution AGCM and a 3-D ice-sheet model, Ann. Glaciol., 42, 433-440, 2005.

Zweck, C. and Huybrechts, P.: Modeling of the northern hemisphere ice sheets during the last glacial cycle and glaciological sensitivity, J. Geophys. Res., 110, D07103, doi:10.1029/ 2004JD005489, 2005. 